\title{
Critical Discourse Analysis of Barack Obama's 2012 Speeches: Views from Systemic Functional Linguistics and Rhetoric
}

\author{
Bahram Kazemian \\ Department of English, Tabriz Branch, Islamic Azad University, Tabriz, Iran \\ Somayyeh Hashemi \\ Department of English, Tabriz Branch, Islamic Azad University, Tabriz, Iran
}

\begin{abstract}
In the light of Halliday's Ideational Grammatical Metaphor, Rhetoric and Critical Discourse Analysis, the major objectives of this study are to investigate and analyze Barack Obama's 2012 five speeches, which amount to 19383 words, from the point of frequency and functions of Nominalization, Rhetorical strategies, Passivization and Modality, in which we can grasp the effective and dominant principles and tropes utilized in political discourse. Fairclough's Critical Discourse Analysis frameworks based on a Hallidayan perspective are used to depict the orator's deft and clever use of these strategies in the speeches which are bound up with his overall political purposes. The results represent that nominalization, parallelism, unification strategies and modality have dominated in his speeches. There are some antithesis, expletive devices as well as passive voices in these texts. Accordingly, in terms of nominalization, some implications are drawn for political writing and reading, for translators and instructors entailed in reading and writing pedagogy.
\end{abstract}

Index Terms - critical discourse analysis, ideational grammatical metaphor, rhetorical devices, Passivization, modality

\section{INTRODUCTION}

Language has a fundamental role in the conveyance of political orators' staged-managed and pre-planned goals to the audience in order to provoke, prevail, and persuade the audience toward the intended goals and meanings (Woods, 2006). Language is not independently powerful; it obtains power through the use of powerful orators and politicians etc. This elaborates why the language utilization of those influential people can be studied critically and with close scrutiny. Power is signified, for instance, by grammatical forms within a text or a text's genre (Renkema, 2009). The focal point of Discourse Analysis (DA) is any form of written or spoken language, such as political speeches; it concerns the sorts of devices and strategies people utilize when engaged in various discourses, such as emphatic tropes, the use of metaphor, nominalization, Passivization and choice of particular words to indicate power relations, and so on. Renkema $(2009$, p. 1) defines discourse studies as "the discipline devoted to the investigation of the relationship between form and function in verbal communication".

Halliday and Matthiessen $(1999,2004)$ draw a distinction between two major types of Grammatical Metaphor (GM), i.e. Ideational Grammatical Metaphor (IGM), focus of this study, which incorporates nominalization and process types and Interpersonal GM that includes modal metaphor and mood metaphor. In terms of metaphor of nominalization, Halliday (1994, p. 352) argue that nominalization "is the single most powerful resource for creating grammatical metaphor". Through this device, processes (verbs) and properties (adjectives) are construed metaphorically as nouns, enabling an informational dense discourse. Kazemian, Behnam and Ghafoori (2013) demonstrate that GM of nominalization is a resource language used to compact information by conveying concepts in metaphorical form which is very valued as a way of expressing objectification, abstraction, ambiguity, information density, formality as well as a mark of prestige and power.

In traditional grammar, rhetoric was the study of style through grammatical and logical analysis. But new rhetoric, common in North American, is the study of how effective writing achieves its objectives. The term rhetoric in this new sense, focus of this study, offers an analytical lens to investigate and concentrate on how to convey oneself accurately and effectually in connection with the subject of writing or speech, and the audience, and to employs methods to identify the relations between texts and contexts. (Jost \& Olmsted, 2004). Rhetorical devices employed in this study are Parallelism, Antithesis, Unification and Cohesivation and Expletive, each of which will be thoroughly enlightened in the followings.

While Critical Discourse Analysis (CDA) concentrates on language in its socio-cultural context and the ideological assumptions established through interaction and texts, rhetorical analysis limits its focal point to political interaction and explores to find patterns of goals, interests and joint assumptions underlying persuasive actions (Jorgensen \& Phillips, 2002). The aim of this study is to reveal implicit meanings in Obama's speeches in terms of nominalization, 
Passivization, modality and rhetorical devices and to disclose what he really wanted the audience to know and believe and what he really wanted to achieve. By utilizing these strategies, despite the fact that this study intends to investigate Obama's speeches to pinpoint the frequency and purposes of employing the devices in the texts, its objective is also to scrutinize the associations among language, ideology and power and to grasp how political rhetoric is employed to convince the people to acknowledge, sustain and advocate its policies. The employment of these apparatus in the speeches is just to inquire into political rhetoric from different dimensions.

\section{THEORETICAL FRAMEWORKS}

Analytical methodology concerning this article is IGM within SFL proposed by Halliday (1994), Fairclough's CDA as well as rhetorical strategies. SFL is usually regarded the major substructure of CDA and other theories in pragmatics. To Young \& Harrison (2004) and Renkema (2009), three popular disciplines to the analysis of authentic text are CDA, SFL, and DA; and strong interdisciplinary bonds exist between SFL and CDA. In order to have critical views from various aspects in this study, an effort was made to integrate perspectives from three independent but inter-related realms viz SFL, CDA and rhetoric.

\section{A. Systemic Functional Linguistics}

SFL mainly concerns itself in how people utilize language together to achieve everyday social life and how social worlds are, in exchange, established in and through language. This interest leads to investigations of how language is structured to achieve socio-cultural meanings. SFL therefore focuses on the analysis of texts, considering relationship to the social context in which they occur. SFL initiated by Halliday is one of the most remarkable and worthwhile theories, and language is regarded as a system organizing into three levels or strata related by realization as such semantics, or the system of meaning, is realized by lexico-grammar, or the system of wording; and lexico-grammar is realized by phonology or the system of sounding. The term grammar stands for lexico-grammar. The lexicon area or lexis is not a separate component, but simply the most delicate end of the unified lexico-grammar (Taverniers, 2002). As Halliday and Webster (2009) elaborate, semantic system is organized into three main functional components, or metafunctions. The three components are: ideational; interpersonal; and textual. Equivalent to each constituent is a small number of distinctive systemic groups of systems with strong interrelationships within each cluster. The three metafunctions function in parallel with the other two. A clause is the complex realization of options from these three functionalsemantic components.

GMs can be recognized in terms of the metafunctions. Halliday and Martin (1993, p.79) define GM as "a substitution of one grammatical class, or one grammatical structure, by another"; for example, your struggles instead of he struggled. As formerly stated, IGM is twofold: nominalization and process types. Nominalization has been of particular importance in the evolution of academic language. In political discourse, particularly, nominalization has ideological functions such as removing agency, creating cohesion and applying power. Halliday (1994) has described that congruent is the less variant form of metaphorical expression and it implies that the metaphorical expression can have various congruent forms and vice versa. IGM primarily employs nominal groups to render the process or attribute which should be expressed by verbs and adjectives in nouns. In brief, the major indication of IGM is nominalization. Thus, the process of nominalization expresses actions and events as things or concepts; noun is the most common IGM in the word level. These changes entail removal of human agency or doer inside the clauses (Simon-Vandenbergen, Taverniers, \& Ravelli, 2003).

Simon-Vandenbergen et al. (2003) and Kazemian et al. (2013) have attempted to show that in nominalization, a meaning that was originally understood by one kind of wording comes instead to be construed by another. Thus, for instance, processes are congruently construed as verbs; in illegal immigration, however, a process (to immigrate illegally) is realized in the form of a noun (immigration). But nouns congruently construe entities, not processes; so something that started off as a doing, namely immigrate, is being reconstructed as if it was a thing as the following instance:

(1) a. to meet the challenges we can only solve together: reducing our deficit; reforming our tax code; fixing our immigration system; freeing ourselves from foreign oil (IGM).

b. to meet the issues we are challenging with and the way to ....: to reduce our deficit; to reform the code and the way people are to tax; to fix the system where people immigrate; to free ourselves ... (Congruent).

In order to identify the metaphorical essence and process types of a non-congruent expression, it is necessary to compare it with its counterpart congruent realization. The grammatical variation between congruent and non-congruent domains is applied to transitivity compositions, and it can be analyzed in terms of the functional construction of these compositions (Thompson, 2004). Process is the core constituent of the transitivity system. In SFL, the processes of human activities and natural world are divided into six process types: material (2a), mental (2b), relational (2c), behavioral (2d), verbal (2e) and existential (2f) as the following examples:

(2) a) An accident destroyed her ballet career.

b) There are many reasons to suppose that he was familiar with those tactics.

c) This area is infamous for drugs.

d) Nora laughed so much that she nearly cried. 
e) If you would like to discuss the matter further, please call me.

f) Suddenly there was a loud explosion.

TABLE 1

PROCESS TYPES IN ENGLISH

\begin{tabular}{|l|l|l|}
\hline Process types & $\begin{array}{l}\text { Category } \\
\text { meanings }\end{array}$ & Example \\
\hline $\begin{array}{l}\text { Material : } \\
\text { Action }\end{array}$ & $\begin{array}{l}\text { 'doing' } \\
\text { 'happening' }\end{array}$ & The army shelled the innocent civilians. \\
\hline Behavioral : & 'behaving' & She wept for the loss of her mother. \\
\hline Mental: Perception & feeling, sensing & $\begin{array}{l}\text { I heard a noise outside. } \\
\text { The girl loved her mother. }\end{array}$ \\
Affection, Cognition & emotive & He described the procedure. \\
\hline Verbal: & 'saying' & Those apples are rotten. \\
\hline Relational & 'being' & Maybe there's some other darker pattern. \\
\hline Existential: & 'existing' &
\end{tabular}

The above table, adopted from Martin, Matthiessen and Painter, 1997, p. 228), depicts the process types and their category meanings with some instances in English. There is a family of linguistic procedures- of which SFL and CDA are related- that is socially oriented, essentially affected by defining the link of language, text, and social life. Functional descriptions endeavor to elucidate the nature and structure of language according to what it has to do.

Many CDA studies (Fairclough, 2003; Woods, 2006) uncover that political liability and the power hierarchy in social relations are features that specify linguistic choices such as nominalization and passive voicing. Fairclough's studies reveal such ideological influences in discursive structures. Fairclough (2003) demonstrates that the exclusion and inclusion of social actors can be syntactically manipulated. He comments: "There are many motivations for exclusion, such as redundancy or irrelevance, but exclusion many be politically or socially significant" (p. 149). The discourse analysis carried out by Fairclough explores the use of syntactic transformations such as nominalization which is a development of Halliday's grammar.

\section{B. Critical Discourse Analysis and Rhetoric}

A great deal of attention has been given to how language is used in political discourse; because it is assumed that they are intimately intertwined. According to Woods (2006), politics is a struggle for power in order to put certain political, ideological and social ideas into practice. In this process, language plays a fundamental role, and every political action is prepared, accompanied, affected and played by language. Political rhetoric is highly stage-managed for and by the media; it leans heavily on devices such as slogans and snappy expressions, parallelism, rhetorical strategies, passive voice and modality as well as nominalization. Meaning, in particular, can be a highly political issue, and most of the time orators are frequently concerned to manipulate meaning, i.e., to color our perception of political trends, policies, actions, who exploit an expertise in semantic engineering in order to persuade us of, indeed to construct, political realities. In addition, they are carefully designed to signal the right moment for the audience to break into spontaneous applause, to ponder over the delivered messages etc. Persuasive linguistic techniques are commonplace in the language of politics, whether it be the exploitation of persuasive rhetorical tropes or even rhyme as a form of sound play. The linguistic devices that the political genre employs can end up having far-reaching effects which lie at the heart of CDA and rhetoric.

CDA is an interdisciplinary analytical viewpoint which looks into the relationship between power and discourse, and particularly it investigates the way in which authority, dominance and social inequality are constructed, sustained, reproduced and resisted in the discourse of written texts and spoken words. CDA aims to unpack the common-sense social and cultural ideologies which are embedded in all the forms of language that we use (Fairclough, 2006).

Critical approaches to discourse have been employed to study variety of discourses and they are particularly significant in relation to the study of politics. The construction of political systems, where individuals need to be persuaded to act collaboratively for the welfare of all, seems to rely on the use of a symbolic communication system, and it is quite probable that these two human properties have evolved concurrently. Certainly the power of rhetoric, the oratorical art of manipulating language for persuasive ends, was well grasped in classical times. Rhetorical language is clearly not always honest; it may equally well be used to obscure or twist the truth. Therefore, political rhetoric is designed to lead its audience in the direction of specific thoughts, opinions and ultimately, actions. The goal for politicians is not primarily to present facts, but to be persuasive (Woods, 2006; Jost \& Olmsted, 2004).

Fairclough's (2003) approach to CDA is also unique in that he deals with the Foucauldian notion of discourse with a strong focus on linguistic analysis of textual materials and he has developed linguistic means of analyzing textual forms and structures. This type of study is valuable as it bridges the gap between the structural form of language and the external social world it tries to represent. This way, a deeper understanding of discourse can be obtained. For verification of the linguistic associations to such subjectivity, Fairclough embraces the framework initiated by Halliday's SFL (1994) to analyze discourse at the clausal level. The correlation between discourse and social commitments can be detected through a grammatical analysis of clausal structures. According to Fairclough (1989), society and discourse operate in tandem to constitute each other. Discourse shapes the way people think and the linguistic features are vehicles which carry ideologies and perceptions of the social world. 
This paper attempts to unveil ideologies which are covert in these texts. The main analytical tools of this paper draw largely from IGMs in SFL, rhetorical strategies and the framework of CDA in which Fairclough has initiated to seek the relationship between discourse and society, and has stressed the importance of observing the grammatical aspects of discourse.

\section{AN INTRODUCTION TO SPEECHES}

Mr. Obama has delivered 24 speeches plus three presidential candidate debates with Mr. Romney in 2012. Five speeches are chosen haphazardly based on their political delivery importance to pinpoint rhetorical strategies, nominalization, passivization and modality incorporated in them. All the speeches are available at www.americanrhetoric.com, and are delivered Jan. $5^{\text {th }}$ on military strategy; Jan. $24^{\text {th }}$ on Third Presidential State of the Union; Sep. $6^{\text {th }}$ on Presidential Nomination Acceptance; on Sep. $25^{\text {th }}$ in the United Nations General Assembly and finally Nov. $7^{\text {th }}$ on Second Presidential Election Victory Speech respectively. It is assumed that ascertaining the context can assist readers comprehend coherent associations across utterances. Schiffrin (1994, p. 363), states that "the interaction between text and context implies a procedure of combining linguistic meaning with context to derive inferences about messages". These speeches, approximately 19380 words, are used as the corpus to identify and analyze the frequency and functions of nominalizations and their relevant process types, and rhetorical strategies as well as Passivization and modality. After thorough reading, in order to detect IGMs in these texts and to render them in congruent realm to find their process types, the ideas of Halliday (1994), Halliday and Matthiessen (1999, 2004) and Martin et al. (1997) are used as the most comprehensive models to analyze IGMs, because Halliday (1994) argues that for identifying process types, each metaphorical domain must have its equivalent congruent wording. In addition, other strategies are pinpointed as well to determine their functions and frequency in the texts.

\section{DATA ANALYSIS}

The major objective of the current study is to inquire into IGM, rhetorical tropes, passivization, modality and their respective frequencies and functions in the corpus comprising five political addresses. The choice of the speeches is on the basis of their skillful political rhetoric and oratory in which criteria for selecting these strategies are as follows: Primarily, agentless passives leave an actor unclear and are mainly used to represent ambiguity and concealment- and this is true of nominalization as well. Then, an insight into the essence and the functions of nominalization, persuasive rhetorical strategies in political discourse can aid the researchers to make exhaustive and intelligible presentations of these strategies and assist readers to recognize their key importance for the comprehension of political speeches. Eventually, an effort is made to set out an outlook of interrelationship of language and society, with the emphasis on power and ideology.

\section{A. Nominalizations in Political Speeches}

Nominalization is the main lexico-grammatical characteristic of the most languages. Simon-Vandenbergen et al. (2003) state that processes can be symbolized as things rather than actual happenings. A specific technique, namely nominalization, has to be employed to fulfil this task. Through nominalization, a basic proposition comprising a subject, verb and an object can be turned into a much simpler entity or a noun phrase as follows:

(3) ...our troops have the equipment and capabilities.... (IGM)

In the above example, the process (to equip) and the quality (capable) are rendered in entities. The use of IGM helps to contract long sentences to a noun or noun phrases and compact more information in a clause. Another consequence of IGM is that fundamental aspects of the process and some information are left unspecified: in particular, we don't know about who or what; as such there is no manifestation of the timing of the process or an agent.

Halliday and Webster (2009) draw our attention to the fact that IGMs typically take place in syndromes, where every element has undergone a metaphoric shift. Moreover, in several circumstances, nominalizations are essential since congruent clauses would impede the smooth flow of information in the discourse as follows:

(4) a. ... in the capabilities that we ..., including intelligence, surveillance and reconnaissance, counterterrorism, countering weapons of mass destruction and the ability to operate... where adversaries....

b. these achievements are a testament to the courage, selflessness and teamwork of America's Armed Forces.

Comparatively, the more probable congruent version of (b) is: what we have achieved can be testified to show that American's arm forces are courageous, are selfless and they work as a team. This clustering of interdependent properties is what produces the characteristic style of a contemporary political texts. The orator couldn't possibly convey his intended meaning through the congruent domain and capture the attention of the audience. The above instances are compound IGMs where lexical density, objectification, impersonality and ambiguity are manifest. Fairclough (2003) claims that the reasons for utilizing such technique could be stylistically or ideologically stimulated, i.e. nominalization is spatially effectual. Sometimes, several lengthy sentences can also be conveyed by a nominal. Due to this productivity and facility of being able to contract large amounts of information into a single word, nominalization is a widely exploited linguistic technique in political and many other discourses. 
Woods (2006) explicates that nominalization helps to avoid expressing definite people in the event described and it can also establish an impersonalizing and remoteness effect through the removal of participants. Nominalization is a syntactic conversion which transforms whole clauses into a noun or nominal phrases; this enables it to obtain agency by capturing the doer position and also presents an abstract feature to an action/event:

(5) And on every issue, the choice you face ... It will be a choice between two different paths...; a choice between....

By using three IGMs (choice) in a row, the audience attention is distracted from the process that is actually occurring and managed instead to the product of the process. The force of these expressions distract the audience consideration from such questions as: What is being chosen? Who is choosing? etc. Discourse analysist would say that "the process is backgrounded and the effects foregrounded" (Woods, 2006, p. 73).

All the above mentioned characteristics such as objectivity, abstractness, encapsulation, impersonality and remoteness, lexical density and ambiguity, as Halliday and Martin (1993) and Kazemian et al. (2013) argue, are byproducts of IGM. The following IGMs samples are selected randomly from these texts:

TABLE 2

SAMPLES OF IGMS IN FIVE SPEECHES

\begin{tabular}{|c|c|c|c|}
\hline \multicolumn{4}{|c|}{ 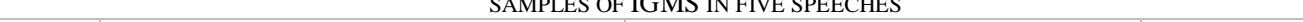 } \\
\hline No. & Metaphorical wording & possible Congruent wording & Process type \\
\hline 1 & into harm's way & into a way which is harmful & relational \\
\hline 2 & $\begin{array}{l}\text { No challenge is more urgent. No debate is } \\
\text { more important }\end{array}$ & $\begin{array}{l}\text { there is no need to challenge because.... } \\
\text { there is no need to debate, because.... }\end{array}$ & $\begin{array}{l}\text { material } \\
\text { verbal }\end{array}$ \\
\hline 3 & $\begin{array}{l}\text { you should get help financing a new plant, } \\
\text { equipment, or training for new workers }\end{array}$ & $\begin{array}{l}\text { you should get help and your new plant } \\
\text { must be financed, must be equipped and } \\
\text { get help to train ... }\end{array}$ & $\begin{array}{l}\text { material } \\
\text { material } \\
\text { material }\end{array}$ \\
\hline 4 & difficulty and uncertainty & to be difficult and uncertain & $\begin{array}{l}\text { relational } \\
\text { relational }\end{array}$ \\
\hline 5 & of growth and prosperity & to grow and to be prosperous & $\begin{array}{l}\text { material } \\
\text { relational }\end{array}$ \\
\hline
\end{tabular}

In the above Table (2), there are ten processes rendered in nouns, i.e., abstract entities such as difficulty and uncertainty (4), growth (5), etc. These are now no longer expressing actions, but are focused on concepts. As it was noticed, IGM instances in the texts are employed to perform multiple important functions as the following example:

(6) You elected me to tell you the truth. And the truth is, it will take....

In the clause ... the truth. And the truth is..., nominalization is utilized to make IGM. The congruent domain might be ... to be true with you. And It is true that.... In the non-metaphorical expression, true is in the role of quality, but in metaphorical expression, true is rendered in truth which is in the role of carrier. By this kind of nominalizing, Mr. Obama would like to comment on a fact -a truth- which still exists. In addition, only by one word with the function of subject, the audience could comprehend that the delivered message must incorporate significant information about a fact which nobody knows.

TABLE 3

FREQUENCY AND PERCENTAGE OF PROCESS TYPES IN THE SPEECHES
\begin{tabular}{|l|l|l|}
\hline Process types & Frequency & Percentage \\
\hline material & 881 & 4.56 \\
relational & 542 & 2.81 \\
mental & 134 & 0.69 \\
verbal & 105 & 0.54 \\
behavioral & 16 & 0.08 \\
existential & 4 & 0.02 \\
Total & 1682 & 8.7 \\
word count & 19282 & - \\
\hline
\end{tabular}

In these five speeches, out of 1682 nominalizations, 881 go for material, 542 for relational, 134 for mental, 105 for verbal, 16 for behavioral and 4 for existential processes.

\section{B. Rhetorical Strategies}

It is obvious that rhetorical study is concerned with the modes of persuasion and persuasion is clearly a sort of demonstration. Rhetorical Analysis examines persuasive, emphatic, effective, contrasting strategies etc. in the realm of political rhetoric and other discourses. Besides, rhetorical devices are utilized to improve the effectiveness, clarity, emphasis, association, and focus. Sometimes a certain strategy belongs primarily to a single category, as for instance an Expletive, used mainly for emphasis; but parallelism, assists to order, illuminate, highlight and adds beauty to the thought and clauses (Van Haaften, Jansen, De Jong \& Koetsenruijter, 2011).

\section{Parallelism}

Parallelism is re-occurrence syntactical and lexical similarities and is employed across or inside sentences or even inside clauses and phrases (Cuddon, 2012). Upon inquiring into these speeches, one can find both syntactic and lexical parallels in which they are the influence of reiteration of the same words or clauses or even certain connections between 
words, mostly associated to the same parts of speech, such as verbs or nouns. It is also worth noting that there is a large number of parallel structures in these texts in which not only they call the audience attention and underscore the topic but also they add balance and rhythm as well as they clarify and beautify the sentences. Meanwhile, categorizing items, together in parallel constructions, results in unification, either they express the impression and efficiency that are in some way related, or, to intentionally invite comparative investigation of them. Parallel subjects or parallel verbs and adverbs or verbs and direct objects, etc. are utilized to indicate Parallelism as the following instances:

(7) a. we've built the best-trained, best-led, best-equipped military in history.

b. No bailouts, no handouts, and no copouts.

c. It would threaten the elimination of Israel, the security of Gulf nations, and the stability of the global....

All the above instances are extracted from the speeches which are deliberately employed by the orator to signify and add clarity, equality, emphasis, importance, balance, persuasion, focus and beauty to them. Out of 412 Parallel structures in these speeches, 20 is utilized in text one, 73 in text two, 203 in text three, 68 in text four and 47 in text five. There are two separate parallel tropes in the following excerpt to indicate effective and emotive connections among sentences and to make the audience mesmerized by the paramount importance of the topic.

(8) There is no speech that justifies.... There are no words that excuse the .... There's no video that justifies an .... There's no slander that provides an ... to burn a ..., or destroy a school ..., or cause death and ....

In text four, six parallel structures are applied by the word (because) to emphasize and link them together by representing cause and effect relationships and also by utilizing parallelism and antithesis in some sentences the orator attempts to take the paramount importance of the issues into the audience account. Employing series of parallel nouns, verbs or phrases in sentences, despite all the above properties, are highly persuasive where they symbolize a sense of emotional, intellectual or sensory pressure in the audience.

2 Antithesis and Expletive

Antithesis is defined by Cuddon (2012) as the contrasting ideas sharpened by the use of opposite or noticeably different meanings and it creates a transparent, contrasting association between two ideas by connecting or juxtaposing them together, often in parallel structure. An Expletive device is also a single word or a short phrase, usually suspending normal flow of speech, employed to lend emphasis to the words instantly proximate to the expletive. In order to highlight disparities in various topics, Mr. Obama applies the effects of antithesis in contradictory and parallel structures as in:

(9) a. the growth in the defense budget will slow, but .... It will still grow....

b. tyranny is no match for liberty.

c. we're not going back. We are moving forward.

d. ... climate change is not a hoax. More droughts and ... are not a joke. They are a threat to....

e. we do not ban blasphemy against our most sacred beliefs.

These antithesis structures are juxtaposed in the texts to show and stress contradictory comments and to call the audience attention to differentiate between facts and fictions as well as opinions. 117 antithesis expressions are applied in the five speeches to establish a certain and systematic link between opinions. The following example extracted from text four, contain both antithesis and parallel structure as well as an expletive:

(10) But understand, the attacks... are not simply an assault on .... They are also an assault on the very ideals....

The phrase (but understand) is an expletive device to underline the following sentences about the assault on American embassy. The extract incorporates parallelism and antithesis as well. Antithesis, which is closely corresponded to parallelism, is a strategy used by Mr. Obama to strengthen the rhetorical influence and emotional force of his oratory. Some useful expletives employed in the texts include the following: Indeed, in short, in fact, as strongly as, absolutely, but understand, certainly, etc. Finally, it is found that there are 158 expletives applied in the texts in total.

\section{Unification and Cohesivation Strategy}

If the speeches are read and listened critically, and meticulously, it will be grasped that in every clause or a sentence, there are some hidden meanings await to be disclosed and signal to be noticed by the audience and readers. In political discourses, the strategic employment of we-groups (we, our and us) serve to establish a unified relationship between politicians and the public.

Fairclough (1989) maintains that pronouns in English do have correlative values of various sorts, i.e., the choice between we and you is bound with associations of power and solidarity. To Fairclough, there are generally two types of we pronouns, namely, inclusive we, which includes the audience as well as the speaker, and exclusive we, which refers to the speaker or writer plus one or more others, but does not incorporate the addressee(s).

Mr. Obama has used a large number of we-groups in the texts; the use of these devices not only unify the orators with the audience but also they identify themselves as one belonging to the society, narrowing or bridging the invisible gap between the stage and the crowd. This subdivision of constructive strategy is largely employed to signify a sense of solidarity and cohesivation to the crowd as follows:

(11) a. In short, we've succeeded in defending our nation, ... to our enemies, ..., and we've restored.... That makes us safer and it makes us stronger.

b. We should start with our tax code. 
As it is obvious in most instances, there is an ambiguity in that strategy as well, because sometimes it is not clearly distinctive and transparent that by we, who he refers to: is it inclusive or exclusive? By we does he incorporate the audience or just embrace his Administration? In above example (11a), we-groups, might refer to his government; and in example (11b), for instance, the first one (we) probably refers to his Administration, but by the second one (our), he definitely unifies himself with the crowd. There are plenty of inclusive and exclusive we, probably the most used words of the speeches, utilized skillfully by the orator in the speeches to denote solidarity or implicitly to distance his office with the audience. By applying inclusive we, Mr. Obama, in this case, regards himself as a member of the society to which he speaks. Whether he talks about the preceding accomplishments or the future plans, the orator asserts them to represent unity and commonality, which means that he splits responsibility for everything being mentioned to the audience. Consequently, the audience seems to turn into a co-author of the speech, provided that they consent to it, and they do so by bursting into frequent and rapturous applause. Simply put, the president speaks on behalf of the American people.

\section{Modality and Passivization}

\section{Modal verbs}

Modality is the semantic category primarily related to the expression of alternative thoughts and attitudes and is the means by which a speaker's attitude towards what they are saying is conveyed (Renkema, 2009). To Fairclough (1989), Modality is to do with speaker or writer authority as well, and there are two aspects to modality, based on what direction authority is oriented to. Primarily, the status of the authority of one person pertinent to others, relational modality is engaged (the focus of this study). Secondly, a matter of the speaker or writer's authority in regard to the truth or possibility of a depiction of reality is presented, expressive modality (Fairclough, 1989; Downing \& Locke, 2006). Relational modality is demonstrated by modal auxiliary verbs like may, must, should, can, ought, etc., as follows adopted from Halliday (1994, p. 362):

TABLE 4

MODAL VERBS

\begin{tabular}{|c|c|c|c|}
\hline & Low politeness & Median politeness & High politeness \\
\hline Positive & Can, may, could, might & $\begin{array}{l}\text { Will, would, should, } \\
\text { shall }\end{array}$ & Must, ought to, need, has/had to \\
\hline Negative & $\begin{array}{l}\text { Needn't, need to, } \\
\text { have to }\end{array}$ & $\begin{array}{l}\text { Won't, wouldn't, } \\
\text { shouldn't }\end{array}$ & $\begin{array}{l}\text { Mustn't, oughtn't to, can't, couldn't, } \\
\text { mayn't, mightn't, hasn't/hadn't to }\end{array}$ \\
\hline
\end{tabular}

Modal auxiliaries are implicit means of modality of possibility and necessity with high, median and low standards. Based on Halliday's (1994) categorization, have to, must, need and ought to are modal verbs of high standard, would, will, shall, and should are modal verbs of median standard, and can, may, might, and could of low standard. Fairclough (2003) proposes that in terms of grammatical choices, a key dimension of the analysis involves investigating modality which represents outlooks into commitments to truth, obligation and necessity. For instance:

(12) ...but teachers must inspire; principals must lead; parents must instill a thirst for learning; and students, you've got to do the work. ... I promise we can ....

the modal (must) is employed three times and have got to and can are applied once in the above example which are expressing strong conviction based on deduction or inference from evidence; they display obligation, i.e., authority's attitude oblige them to do so. Obligation can be thought of an inevitable duty or requirement, realized by must, have (got) to and must can have the force of a direct command. This force grows out of the fact that in definite cultural contexts, the speaker has authority over the audience, and the speaker takes the responsibility for the action being conducted.

TABLE 5

MODALITY ANALYSIS OF THE SPEECHES

\begin{tabular}{|l|l|l|l|l|l|l|l|l|l|l|}
\hline \multirow{2}{*}{ Texts } & Total & \multicolumn{2}{|l|}{ Low value } & \multicolumn{2}{l|}{ Median value } & \multicolumn{2}{l|}{ High value } \\
\cline { 3 - 11 } & No. & Positive & Negative & Total & Positive & Negative & Total & Positive & Negative & Total \\
\hline 1 & 1548 & 3 & 5 & 8 & 16 & 2 & 18 & 4 & 4 & 8 \\
\hline 2 & 7073 & 37 & 12 & 49 & 78 & 15 & 93 & 11 & 22 & 33 \\
\hline 3 & 4548 & 42 & 10 & 52 & 48 & 6 & 54 & 18 & 8 & 20 \\
\hline 4 & 4042 & 18 & 2 & 20 & 30 & 3 & 33 & 21 & 11 & 32 \\
\hline 5 & 2071 & 15 & 3 & 18 & 15 & 5 & 20 & 2 & - & 2 \\
\hline Total & 19282 & 115 & 32 & 147 & 187 & 31 & 218 & 56 & 45 & 95 \\
\hline
\end{tabular}

The above table (5) depicts the frequency and percentage of modal auxiliaries exploited by Mr. Obama in the speeches. According to the statistics, it is manifest that modal verbs are used to refer broadly to a speaker's outlook and judgment towards the truth of a statement expressed by a sentence with an average of $2.38 \%$ in the whole speeches. The high percentage of the application of modal verbs is proper to the speaking since the addresses are delivered in spoken form. In comparison to other verbs, modal auxiliaries are more readily pinpointed and then admitted, due to the fact that, at the time of listening to the speeches, the audience has no time to ponder. Consider the following examples: 
(13) a. Finally, ... defense budget that will flow from this strategy. The details will be announced .... Some will no...; others will say that .... It will be easy to .... But I'd encourage....

b. Some may be Democrats. Some may be Republicans. But that doesn't matter.

c. We can give... or we can start... We can help big factories.... We can create a million ....

The above instances represent different modalities by which the speaker commit themselves to his statements to varying degrees. The speaker puts himself in a position whereby he can give the audience permission or obligate them to do something. It is worthy of mention that in order to withhold permission from, or impose obligations upon the audience, the orator based on the authority and power relations employs various modalities in various topics. It is accurately implicit authority claims and implicit power relations of the sort elaborated here that make relational modality a matter of ideological interest.

\section{Passive Voice}

Many CDA studies conclude that political commitments and the power hierarchy in social relations are elements that specify linguistic choices such as nominalization and passivization. Fairclough's studies $(1989,2003)$ have indicated the ideological effects in discursive constructions. Generally, obscuring the act of agency is typically attained by the use of the passive voice and nominalization. Passivization represents the speaker or writer the option to remove the agent altogether, known as an agentless passive construction (Simpson, 1993). In passive clauses, the agent in fact becomes a circumstance, and circumstances can be left out without making the sentence ungrammatical, e.g.-- Chris was killed in the city that he helped to save-- This sentence is, grammatically, a perfectly acceptable clause, even though it has no Agent (Renkema, 2009). It is obvious that, in this instance, the passive voice foreground the themes and background the agents. In these texts, passive voices are mostly accompanied by nominalization each of which tends to provide the anonymity of the agents. There are 124 passive sentences used in the speeches in which the agents are intentionally left implicit and silenced. Consider the following example:

(14) On the same day our civilians were killed in Benghazi, a Turkish police officer was murdered in Istanbul ...; more than 10 Yemenis were killed in ...; several Afghan children were mourned by...they were killed by a suicide bomber in Kabul.

The use of all above passive voices might be due to the fact that the impact of the action is much more important that the actor. As van Dijk (2000) argues, the agency might be regarded less prominent by shifting the expression as in: ' $a$ suicide bomber killed several Afghan children' into 'several Afghan children were killed by a suicide bomber'. Indeed, the agent at times may be totally left hidden by passive as in: 'several Afghan children were killed' or by employing the nominalization such as 'Killing of Afghan Children'; in which the last one represses the agency of such gross misconduct. It is claimed that such a strategy encrypts ideological bias in favor. Thus, responsible individuals are defocused and removed from the surface realization of the process, and are concealed from the readers of the text or the audience of the speech. Other expressions comprised of passive sentences are as follows:

(15) a. The impulse ... may initially be focused on..., but over time it cannot be contained. The same impulses toward extremism are used to justify....

b. Over the next few years, big decisions will be made in Washington....

c. Terrorist plots must be disrupted. Europe's crisis must be contained.

Closer scrutiny of the speeches reveals that all the utilized strategies and devices in this study permeate in most paragraphs as follows:

(18) This is the choice we now face. This is what the election comes down to. Over and over, we've been told by our opponents that bigger tax cuts and fewer regulations ... government can't do everything, it should do almost nothing. If you can't afford health insurance, .... If a company releases toxic pollution into the ..., well, that's the price of progress. If you can't afford to start ..., take my opponent's advice and ....

In the above example, all strategies such as nominalization (choice, election, tax cuts, health insurance, pollution, progress, and advice), parallelism (this is, if clauses), antithesis (bigger-fewer), expletive (over and over), unification (we, our), modal verbs (can't, should) and eventually, passivization (we've been told) are used to indicate Mr. Obama's art of oratory and political rhetoric.

\section{DisCUSSION AND CONCLUSION}

The discussion of the findings is explicated as follows and in terms of IGM, they corroborate Halliday and Matthiessen's (2004) proposal that a material process type should be dominant in the analysis of IGM or transitivity. Revising the annals of GM indicates that IGMs are highly significant since they compress information and effectively systematize known information. Nominalization boosts the density of the information and improve the content of utterances through making sentences into a noun or noun phrases.

After analyzing these speeches based on nominalization, the results display that the most frequently employed types of IGM in these texts are types 1 and 2, i.e., being quality to entity (prosper to prosperity), and being process to entity (grow to growth) respectively; and the most dominant processes are material (881), based on action and happening, and relational (542) which are based on being and having. Nominalizations in theses texts amount to 1682 expressions and the proportion of all processes to the whole words is $8.7 \%$ and this excessive use of material processes is quite dramatic in terms of power relations. Halliday and Matthiessen's (2004) argue that if one tends to deploy power, it is more 
effectual to deploy it within the domain of doing rather than other processes, because it is not easy to affect how people think, as compared with utilizing physical element to influence how they act. Consequently, it is fundamental to specify who gets to be the doer, where material processes are used.

Unlike material clauses symbolizing the doings of the participants in this study, relational clauses furnish descriptive information about the appearance of the phenomena and the qualities of the pertinent participants. In addition to relational processes, other types of processes, in terms of frequency, are conveyed by mental, verbal, behavioral and existential respectively. In contrast to relational processes concentrating on categorization and explication, mental processes are involved in the depiction of the participants' thoughts, affection and cognition. They reflect the orator's perceptional changes and represent ideologies resided in his consciousness. Verbal processes also indicate the symbolic activities of saying and permit the political orators to voice their concern, objection, sympathy and so on.

In terms of IGM some implications are drawn up to equip those who are pursuing their career as professional political writers or involved in political studies or political pedagogy. It is hoped that studies like this can pave the path by providing effective, efficient and informative particulars and facts for researchers, instructors and EFL students involved in writing, investigating and reading political discourse. Knowing about grammatical complexity of language and the way it works to condense information can also shed light on the seamless process of translation, since translation demands good command of English viz GM and IGM. Lastly, other functions of IGM such as condensation, lexical density, conceptualization, and formality can assist EFL and ESL students to improve their writing and reading.

As shown in the data analysis, some of the rhetorical strategies are regarded as transitional apparatus, as well as to aid the orator to move seamlessly from one portion to another like expletive, while others are employed to represent evidence or information as strongly as possible as antithesis. Still others help associate the whole topics together, making them cohesive, focused, convincing and intentional such as parallelism. Simply put, rhetoric grants you a great deal of power with which to communicate your message by provoking an emotive reply, arousing powerful imagery, or calling upon reliable authorities.

Analyzed CDA concepts in the study are modal verbs and passive voicing. CDA can be practiced for portraying, interpreting, inquiring, and critiquing social context and ideologies reflected in texts. CDA aims to systematically look into relationships between discursive practices, the structural form of language and the external social world (Rogers, 2011). In data analysis, it was noticed that Passivization and nominalization go hand in hand in most clauses and complement each other well. Through Passivization, information about agents at the sentence level are omitted and this agentlessness in clauses is most often achieved by metaphoricity and the use of passive verbs. The passive voices are impressively applied in the context illuminating the serious repercussions of worldwide and nationwide challenges, Mr. Obama's political opponents' actions, his Administration's and people's rights and responsibilities, his office's international diplomacy, terrorism etc. In some sentences, the orator has used by-passive voices (the use of the agent at the end of the clause) to de-emphasize the agent and underscore the event and action. However, in most cases the agent is totally removed and left implicit due to several reasons such as to avoid giving or taking blame or responsibility, to emphasize the effect or action, to make events seem more abstract, or to conceal responsibilities of certain individuals.

To sum up, the analysis of Mr. Obama's 2012 speeches infers that the addresses were prepared by a deft orator and are not impromptu speeches. Meanwhile, multiple linguistic and rhetorical strategies are exploited for the efficiency of the speeches. They are inextricably intertwined and, at times, it is hard to uncouple one from another as they are often multifunctional. The tendency and priority to apply more nominalization, passivization and modal verbs by the political orator in Mr. Obama's speeches are the vital reasons for making his language powerful, impressive, persuasive and ambiguous as well. Primarily, by metaphorizing a process and passive voicing, Mr. Obama can mirror a fact, or express his intended meanings implicitly as in a compact and dense forms. Secondly, nominalization is a means to assist him to expand his discussion cohesively and step by step, which employs compound passages encapsulated in nominal forms as theme. Finally, nominalizations construct and contribute to abstraction, generalization, impersonality, objectification, information load, language economy and cohesion, ambiguity and, of course, beauty of the texts. Upon listening as well as reading Obama's speeches, it will be noticed that, in nearly all paragraphs, there are some eye-catching tropes along with plenty of recurrent syntactical and lexical clauses attracting the audience and readers attention. Besides, it is immediately apparent from the selected speeches that President Obama relies heavily on rhetorical devices, particularly, parallelism tropes and unification strategy. Rhetorical devices investigated in the study are used as persuasiveness properties to improve the effectiveness, clarity, and beauty of the speeches. The aims are to persuade, to inform, to convey personal ideologies, to emphasize inter-relatedness of delivered messages, to signify differentiation, and to demonstrate orator's solidarity with the audience.

\section{REFERENCES}

[1] Cuddon, J. A. (2012). A Dictionary of literary terms and literary theory, $\left(5^{\text {th }}\right.$ ed.) London: Penguin books.

[2] Downing, A. and Locke, P. (2006). English grammar: A university course. London \& New York: Routledge.

[3] Fairclough, N. (1989). Language and power. London: Longman.

[4] Fairclough, N. (2003). Analyzing discourse: Textual analysis for social research. London \& New York: Routledge.

[5] Fairclough, N. (2006). Language and Globalization. London and New York: Routledge.

[6] Halliday, M. A. K. (1994). An introduction to functional grammar (2 $2^{\text {nd }}$ ed.). London: Edward Arnold.

[7] Halliday, M. A. K., \& Martin, J. R. (1993). Writing science: Literacy and discourse. London: Flamer Press. 
[8] Halliday, M. A. K. \& Matthiessen, C. M. I. M. (1999). Construing experience through meaning: A language-based approach to cognition. London/New York: Continuum.

[9] Halliday, M. A. K. \& Matthiessen, C. M. I. M. (2004). An Introduction to functional grammar. London: Edward Arnold.

[10] Halliday, M. A. K., \& Webster, J. J. (2009). Continuum companion to systemic functional linguistics. London: Continuum.

[11] Jorgensen, M. and Phillips, L. (2002). Discourse analysis as theory and method. London: Sage Publications.

[12] Jost, W. \& Olmsted, W. (2004). A companion to rhetoric and rhetorical criticism. Oxford: Blackwell Publishing

[13] Kazemian, B., Behnam, B. \& Ghafoori, N. (2013) Ideational grammatical metaphor in scientific texts: A Hallidayan perspective. International journal of Linguistics, 5 (4), 146-168. http://dx.doi.org/10.5296/ijl.v5i4.4192.

[14] Martin, J. R., Matthiessen, C. M. I. M. \& Painter, C. (1997). Working with functional grammar. London: Edward Arnold.

[15] Renkema, J. (2009). Discourse, of course. An overview of Research in discourse studies. Amsterdam/Philadelphia: Benjamins Publishing.

[16] Rogers, R. (2011). An Introduction to critical discourse analysis in education. New York \& London: Routledge.

[17] Schiffrin, D. (1994). Approaches to discourse. Oxford: Blackwell Publishing.

[18] Simon-Vandenbergen, A.M., Taverniers, M. \& Ravelli, L. (2003). Grammatical metaphor: Views from systemic functional linguistics. Amsterdam: Benjamins.

[19] Simpson, P. (1993). Language, ideology and point of view. London \& New York: Routledge

[20] Taverniers, M. (2002). Systemic-functional linguistics and the notion of grammatical metaphor: A theoretical study and a proposal for a semiotic-functional integrative model. Belgium: University of Gent

[21] Thompson, G. (2004). Introducing functional grammar. London: Arnold.

[22] Van Dijk, T. A. (2000). Ideology and discourse: A multidisciplinary introduction. Barcelona: Pompeu Fabra University.

[23] Van Haaften, T., Jansen, H., De Jong, J. \& Koetsenruijter, W. (2011). Bending opinion: Essays on persuasion in the public domain. Amsterdam: Leiden University Press.

[24] Woods, N. (2006). Describing discourse. New York: Horder Education.

[25] Young, L., \& Harrison, C. (2004). Systemic functional linguistics and critical discourse analysis: Studies in social change. London/New York: Continuum.

Bahram Kazemian was born in Tabriz City, East Azerbaijan Province, Iran in 1980. He obtained his M.A. degree from Islamic Azad University-Tabriz branch, Iran in English Language Teaching. Currently, he is the managing director of Unique Language Center in Tabriz. His major areas of interest are Systemic Functional Linguistics, Bakhtinian studies, Contrastive \& Error Analysis, Discourse Analysis, Critical Discourse Analysis, Rhetoric and EFL.

Somayyeh Hashemi was born in Tabriz City, East Azerbaijan Province, Iran in 1984. She received her degree from Islamic Azad University-Tabriz branch, Iran in English Literature. Currently, she is a lecturer in Osveh University in Tabriz, Iran. Her major areas of interest are Bakhtinian studies, Systemic functional linguistics, Discourse Analysis, Critical Discourse Analysis and Romanticism. 